\title{
Tumor necrosis factor induced protein 3 gene polymorphism and the susceptibility to chronic primary immune thrombocytopenia in Egyptian children: a case-control study
}

\author{
Marwa Abd El-hady ${ }^{1 *}$, Dalia S. Mosallam', Shahira K. Anis², Basma S. Mansour ${ }^{1}$ and Marianne E. Yassa²
}

\begin{abstract}
Background: Primary immune thrombocytopenia (PIT) is an acquired auto-immune disease characterized by decreased platelet count with increased bleeding tendency. The tumor necrosis factor associated induced protein-3 (TNFAIP3) codes for the ubiquitin-modifying enzyme that is indispensable for limiting inflammation. TNFAIP3 singlenucleotide polymorphisms (SNP) has been implicated in the susceptibility to multiple auto-immune diseases. We aimed to study the distribution of TNFAIP3 (r55029939 C>G) SNP and the possible association of the studied polymorphism with the susceptibility to chronic PIT and the response to treatment in a sample of the Egyptian pediatric chronic PIT patients. This is a case-control study performed on 40 chronic PIT patients and 50 age- and gender-matched healthy controls. DNA samples from both groups were tested for TNFAIP3 (rs5029939 C>G) SNP using polymerase chain reaction-restriction fragment length polymorphism assay.

Results: TNFAIP3 (rs5029939 C>G) genotype distribution showed no statistically significant difference between PIT cases and controls [CC $77.5 \%$ vs. 82.5\%, and CG 22\% vs. 18\%, respectively; OR (95\% Cl), $1.323(0.470-0.723) ; p, 0.596$ ]. The minor allele frequency (MAF) of rs5029939-G was comparable between the 2 groups (0.11 vs. 0.09) [OR (95\% Cl), 1.282 (0.484-3.397); $p, 0.617]$. No statistically significant difference was observed between chronic PIT patients carrying the mutant heterozygous genotype (CG) achieving complete response and those with no response [OR (95\% Cl), 1.667 (0.165-16.810); $p$ > 0.05]. The MAF of rs5029939-G was comparable between both groups [OR (95\% Cl), $1.571(0.175-14.111) ; p>0.05]$.

Conclusion: This study showed no liability of patients carrying TNFAIP3 (rs5029939 C>G) polymorphism to develop chronic course of the disease or to achieve complete response to treatment. TNFAIP3 (rs5029939 C < G) SNP plays no role in either susceptibility to chronic PIT in the studied sample of Egyptian pediatric population or their response to treatment.
\end{abstract}

Keywords: Primary immune thrombocytopenia (PIT), Tumor necrosis factor associated induced protein 3 (TNFAIP3), (rs5029939 C < G), Polymorphism, PCR-RFLP and Egyptian children

\footnotetext{
* Correspondence: marwahady79@hotmail.com

'Pediatric Department, Kasr Al-Ainy School of Medicine, Cairo University, Kasr

Al-Ainy St., Cairo 11562, Egypt

Full list of author information is available at the end of the article
}

\section{Springer Open}

(c) The Author(s). 2021 Open Access This article is licensed under a Creative Commons Attribution 4.0 International License, which permits use, sharing, adaptation, distribution and reproduction in any medium or format, as long as you give appropriate credit to the original author(s) and the source, provide a link to the Creative Commons licence, and indicate if changes were made. The images or other third party material in this article are included in the article's Creative Commons licence, unless indicated otherwise in a credit line to the material. If material is not included in the article's Creative Commons licence and your intended use is not permitted by statutory regulation or exceeds the permitted use, you will need to obtain permission directly from the copyright holder. To view a copy of this licence, visit http://creativecommons.org/licenses/by/4.0/. 


\section{Background}

Primary immune thrombocytopenia (PIT) is an acquired auto-immune disease characterized by decreased platelet count $<100 \times 10^{9} / \mathrm{L}$ that presents with bleeding manifestations [1]. The term "chronic PIT" is reserved for patients with immune thrombocytopenic purpura (ITP) lasting more than 12 months [2]. ITP is a heterogeneous disorder of immune dysregulation characterized by loss of immune tolerance to self-antigens situated on the surface of the megakaryocytes and platelets [3]. Numerous abnormalities modulating the cellular immunity with $\mathrm{T}$ cell dysregulation have been implicated in the pathogenesis of ITP such as Th1/Th2 imbalance decreased number and dysfunction of regulatory $\mathrm{T}$ cells, increased cytotoxic $\mathrm{T}$ cell-mediated cytotoxicity, and elevated Th17 cells [4]. Despite the improved understanding of ITP, the etiology remains not totally understood. However, it has been widely accepted that both genetic and environmental factors play an important role in the pathogenesis of ITP [5]. Single-nucleotide polymorphisms (SNP) of inflammatory cytokine genes (e.g., $I L-$ $17 F, I L-10, T N F-\alpha, T N F-\beta, T G F-\beta 1, I L-6, I N F-\gamma$, and $I L-$ $1 A$ ) influences patients' susceptibility to ITP [6]. Besides, genetic variants of inflammation-related genes (e.g. CD24, CD226, FCRL3, IL-2, IRF5, ITGAM, NLRP3, CARD8, PTPN22, SH2B3, STAT4, TNFAIP3, and TRAF1) are associated with different auto-immune diseases [7].

TNFAIP3 is one of the genes implicated in multiple immune disorders by genome-wide association studies (GWAS) [8]. TNFAIP3 (also known as A20) gene is located at chromosome 6q23 and codes for the ubiquitinmodifying enzyme [9]. A20 has amino-terminal deubiquitinating (DUB) activity regulated by the ovarian tumor domain (OTU) and carboxyl-terminal zinc finger $(\mathrm{ZnF})$ domain that sustains E3 ubiquitin ligase activity. A20 is indispensable for limiting inflammation by terminating nuclear factor $\mathrm{kB}(\mathrm{NF}-\mathrm{kB})$ activation through de-ubiquitinating several intermediates of NF-kB signaling [10]. A20 is also a crucial checkpoint in selftolerance by controlling dendritic cells (DCs) activation [11]. In vivo, the A20-deficient mice showed excessive activation of NF-kB signaling causing severe multi-organ inflammation [12] and marked activation of DCs leading to loss of tolerance to self-antigens [13] with development of systemic lupus erythematosis (SLE) symptoms in the A20-deficient mice [11]. Thus, A20 functional deficit might be associated with chronic inflammation and loss of self-tolerance [14].

Several studies showed that TNFAIP3 gene variants were strongly associated with several auto-immune diseases including ITP; however, little is known about the role of TNFAIP3 in the pathogenesis of ITP [15]. He et al. [16] investigated the expression of TNFAIP3 in
ITP and found that decreased TNFAIP3 induced the activation of NF-кB/SMAD7 pathway, leading to dysfunctional mesenchymal stem cells (MSCs) that influence megakaryopoiesis. They demonstrated for the first time that the pathologically reduced TNFAIP3 levels impair the ability of ITP-MSCs to support megakaryocytic differentiation and thrombopoiesis. Therefore, aberrant TNFAIP3/NF-kB/SMAD7 pathway signaling may play a role in ITP pathogenesis. Furthermore, they indicated that TNFAIP3 regulation could be a potential therapeutic strategy against NF- $\kappa B$ signaling in ITP.

The commonly studied TNFAIP3 polymorphisms in ITP include (rs2230926) variant located in exon 3 that affects the DUB domain and, in turn, impairs A20 inhibiting potential [17]. (rs2230926) is caused by amino acid substitution of Phe to Cys at residue 127 in the ovarian tumor (OTU) domain that participates in A20 inhibitory function through de-ubiquitination of adaptor proteins [9]. Cys127 allele product had been shown to be less effective in inhibiting TNF-induced NF-kB activation than Phe127 [17]. (rs5029939) variant is located in Intron 2 in TNFAIP3. Based on the fact that (rs5029939) was in strong linkage disequilibrium (LD) with (rs2230926) in European Caucasian population [18], Dieudé et al. [19] concluded that (rs5029939) possibly mirrors ( $r s 2230926)$ effect on TNFAIP3 but they also recommended further investigations to confirm this. Li et al. [6] showed that TNFAIP3 (rs10499194) variant was significantly associated with a decreased risk of ITP.

Previous studies suggested that TNFAIP3 might be a common susceptibility gene to several auto-immune diseases including ITP. Moreover, the analysis of TNFAIP3 SNPs might guide treatment choices. Psoriasis patients carrying specific TNFAIP3 SNPs respond more effectively to TNF blocking therapy [20]. TNFAIP3 SNP analysis before starting the TNF blocking therapy is beneficial to perform in multiple auto-immune disorders [21]. Taken together, these evidences have led us to hypothesize that TNFAIP3 might be associated with the susceptibility to chronic PIT. In the present study, we aimed to study the distribution of TNFAIP3 (rs5029939 $C>G$ ) polymorphism and the possible association of the studied polymorphism with the susceptibility to chronic PIT and the response to treatment in a sample of Egyptian pediatric chronic PIT patients.

\section{Methods}

The present study was performed on 40 patients diagnosed as chronic PIT as well as 50 age-matched and sex-matched healthy controls not suffering from any chronic illness. These patients attended regular follow up visits at hematology outpatient clinic, between September 2016 and November 2017. Controls were selected from outpatient clinic of the children's hospital 
who presented with acute simple condition as common cold or tonsillitis. The mean age of the patients was 8.14 \pm 3.96 years. Among the 40 patients, 23 patients (57.5\%) were females and 17 (42.5\%) were males. All cases were subjected to careful history-taking and a comprehensive clinical examination. Thrombocytopenia was defined as platelet count $<100 \times 10^{9} / \mathrm{L}$ and documented by bone marrow aspirate. Chronic PIT patients defined as patients having platelet count $<100 \times 10^{9} / \mathrm{L}$ for more than 12 months from presentation. We analyzed the response to treatment. The response criteria of ITP International working group (IWG) were used. "Complete response" (CR) is defined as any platelet count of at least $100 \times$ $10^{9} / \mathrm{L}$. "Response" (R) is defined as any platelet count 30 to100 $\times 10^{9} / \mathrm{L}$ and at least doubling of the baseline count. "No response" (NR) is defined as any platelet count $<30 \times 10^{9} / \mathrm{L}$ or less than doubling of the baseline count [2]. The clinical and the laboratory data of the chronic PIT patients are summarized in Table 1. Informed consent was obtained from all subjects' legal guardians in accordance with the Declaration of Helsinki and the hospital-based ethics committee as well. The study protocol was approved by the council of pediatrics department, held on May 2016.

\section{TNFAIP3 genotyping}

TNFAIP3 rs5029939 (C>G) SNP was tested using polymerase chain reaction-restriction fragment length polymorphism (PCR-RFLP) assay. Briefly, DNA extraction from peripheral blood samples was carried out using the QIAamp DNA Blood Mini Kit (Cat\# 51104; Qiagen, Germany). DNA was stored at $-70^{\circ} \mathrm{C}$ until use. PCRRFLP was performed for TNFAIP3 on Biometra T3000 thermo-cycler using the SYBR Green PCR Master Mix (Cat\# K1071, Thermo scientific) as a double stranded DNA-specific binding dye. In brief, the $25 \mu \mathrm{l}$ reaction mixture contains $12.5 \mu \mathrm{l}$ SYBR Green PCR Master Mix (2×), $5 \mu \mathrm{l}$ DNA, $2 \mu \mathrm{l}$ primer pair mix, and $5.5 \mu \mathrm{l}$ sterile DW. The primers used for amplification were TNFAIP3 forward 5' CGTGTGTCTGTTTCCTTGAGCGTGGTG-3'; Reverse: 5'-GAATAAACCAGCCCTACTGCTA-3'. The PCR parameters were as follows: initial denaturation at $95^{\circ} \mathrm{C}$ for 5 min followed by 35 cycles of PCR reaction at $94^{\circ} \mathrm{C}$ for $30 \mathrm{~s} ; 60^{\circ} \mathrm{C}$ for $60 \mathrm{~s} ; 72{ }^{\circ} \mathrm{C}$ for $60 \mathrm{~s}$; and then $72{ }^{\circ} \mathrm{C}$ for 7 min. Identification of the alleles at each polymorphic site was performed by incubating the PCR product with a restriction enzyme (Fastcut AFL II restriction endoneuclease enzyme (Cat\# R042M), Enzynomics for ( $r s 5029939$ C>G)) followed by electrophoresis through a $3 \%$ agarose gel. These PCR products and digested fragments were separately visualized in $3 \%$ agarose gel with ethidium bromide staining under UV light (Fig. 1). Two bands were detected at 186 and $36 \mathrm{bp}$ in the wild genotype (CC) while three bands were detected at $222 \mathrm{bp}, 186 \mathrm{bp}$, and $36 \mathrm{bp}$ in the mutant heterozygous genotype (CG).

\section{Statistical analysis}

Data were analyzed using SPSS with statistical package version 25. Numerical data were expressed as the mean and SD or median and range as appropriate while qualitative data were expressed as frequency and percentage. For quantitative data, Mann-Whitney test (non-parametric $t$ test) was used to compare between two groups. The genotype and allele frequencies were analyzed and compared between the chronic PIT patients and controls using the Chi square $\left(x^{2}\right)$ test. Exact test was used instead when the expected frequencies is $<5$. Odds ratio (OR) with 95\% confidence intervals (CI) was calculated. A $p$ value $<0.05$ was considered statistically significant.

\section{Results}

The characteristics of the studied chronic PIT patients Our study was performed on 40 chronic PIT patients and 50 age-matched and sex-matched healthy controls. The baseline characteristics of the chronic PIT patients are summarized in Table 1 . The patients were 17 males and 23 females. Their age ranged between 2.6 and 16 years. The clinical characteristics of the patients were obtained by patient clinical examination and reviewing their medical records at the Pediatric Hematology Clinic. The platelet count ranged from 4 to $76 \times 10^{9} / \mathrm{L}$ with a median of $30.5 \times 10^{9} / \mathrm{L}$ at initial diagnosis. Seven patients $(17.5 \%)$ had severe thrombocytopenia. Steroid treatment was given to all the patients while splenectomy was performed in only two patients (5\%). The chronic PIT patients had significantly lower hemoglobin level and platelet count compared to controls $(p<$ 0.001). The TLC showed significant statistical difference between both chronic PIT patients and controls $(10 \pm$ $4.32 \times 10^{9} / \mathrm{L}$ vs. $8.03 \pm 1.84 \times 10^{9} / \mathrm{L}$, respectively, $p$, $0.036)$. No statistically significant difference was observed between both groups as regards age and sex ( $p$, 0.835 and 0.887 , respectively) (Table 2).

\section{TNFAIP3 ( $r 55029939$ C>G) genotyping}

No statistically significant different TNFAIP3 (rs5029939 $C>G$ ) genotype distribution was observed among chronic PIT cases and controls [CC, $77.5 \%$ vs. $82.5 \%$, and CG $22 \%$ vs. $18 \%$, respectively; OR (95\% CI), $1.323(0.470-$ 0.723); $p, 0.596$ ]. The minor allele frequency (MAF) of rs5029939-G was comparable between the 2 groups (0.11 vs. 0.09) [OR (95\% CI), $1.282(0.484-3.397) ; p$, 0.617] (Table 3). Comparison between chronic PIT patients and controls revealed non-statistically significant difference between both groups with no liability of patients carrying TNFAIP3 (rs5029939 C>G) polymorphism to develop chronic course of the disease. 
Table 1 Demographic, clinical, and laboratory data of the chronic PIT patients studied.

\begin{tabular}{|c|c|c|}
\hline \multicolumn{2}{|l|}{ Variables } & \multirow{2}{*}{$\begin{array}{l}\text { Chronic PIT patients }[N=\mathbf{4 0}] \\
17(42.5)\end{array}$} \\
\hline Sex $[N(\%)]$ & Male & \\
\hline & Female & $23(57.5)$ \\
\hline \multicolumn{2}{|l|}{ Age [years (mean \pm SD)] } & $8.14 \pm 3.96$ \\
\hline \multicolumn{2}{|c|}{ Age at initial presentation [years (mean $\pm S D)]$} & $4.51 \pm 2.93$ \\
\hline \multicolumn{2}{|c|}{ Duration of illness [years (mean $\pm S D$ )] } & $3.67 \pm 2.51$ \\
\hline \multirow[t]{3}{*}{ Type of bleeding $[N(\%)]$} & Cutaneous & $21(52.5)$ \\
\hline & Mucous & $2(5)$ \\
\hline & Both & $17(42.5)$ \\
\hline \multicolumn{3}{|l|}{ Severity of bleeding } \\
\hline \multirow[t]{5}{*}{ (IWG bleeding score) [N (\%)] } & Severe life threatening $(4 b)$ & $2(5)$ \\
\hline & Severe non-life threatening (4a) & $5(12.5)$ \\
\hline & Moderate (3) & $16(40)$ \\
\hline & Mild (2) & $16(40)$ \\
\hline & Minor (1) & $1(2.5)$ \\
\hline \multicolumn{2}{|l|}{ Splenectomy $[N(\%)]$} & $2(5)$ \\
\hline \multicolumn{2}{|l|}{ HTN $[N(\%)]$} & $13(32.5)$ \\
\hline \multicolumn{2}{|c|}{ Initial platelet count $\left[\times 10^{9} / /(\right.$ mean $\left.\pm S D)\right]$} & $32.67 \pm 20.01$ \\
\hline \multicolumn{2}{|c|}{ Platelets at the time of sampling $\left[\times 10^{9} /(\right.$ mean \pm SD) $]$} & $124 \pm 72.86$ \\
\hline \multicolumn{2}{|c|}{ Hemoglobin at the time of sampling $[\mathrm{g} / \mathrm{dl}($ mean $\pm \mathrm{SD})]$} & $10.98 \pm 1.45$ \\
\hline \multicolumn{2}{|c|}{ TLC at the time of sampling $\left[\times 10^{9} / /(\right.$ mean $\left.\pm S D)\right]$} & $10 \pm 4.32$ \\
\hline \multirow[t]{3}{*}{ Laboratory response $[N(\%)]$} & Complete response & $6(15)$ \\
\hline & Response & $6(15)$ \\
\hline & No response & $28(70)$ \\
\hline \multicolumn{3}{|l|}{ Treatment received } \\
\hline \multirow[t]{4}{*}{ Initial treatment $[N(\%)]$} & Watchful waiting & $11(27.5)$ \\
\hline & Corticosteroids & $40(100)$ \\
\hline & IVlg & $4(10)$ \\
\hline & Platelet transfusion & $2(5)$ \\
\hline \multirow[t]{5}{*}{ Maintenance treatment $[N(\%)]$} & Oral corticosteroids & $35(87.5)$ \\
\hline & Azathioprine (Imuran) & $24(60)$ \\
\hline & Cyclosporine (Sandimmune) & $8(20)$ \\
\hline & Mycophenolate Mofetil (Cellcept) & $1(2.5)$ \\
\hline & Eltrombopag (Revolade) & $2(5)$ \\
\hline
\end{tabular}

SD standard deviation, IWG International Working Group, HTN hypertension, Hb hemoglobin, TLC total leucocytic count, IVIg intravenous immunoglobulin

Comparison between chronic PIT patients carrying wild genotype (CC) and those carrying mutant heterozygous genotype (CG) revealed a highly statistically significant difference as regard watchful waiting as initial treatment where it was applied in a significantly higher percentage in patients harboring the heterozygous mutant genotype (CG) $(p, 0.007)$. No statistically significant difference was observed between both groups as regards age, sex, age at initial presentation, duration of illness, type and severity of bleeding, hypertension, splenectomy, hemoglobin level, TLC, initial and current platelet count, laboratory response to treatment, initial lines of treatment (other than watchful waiting), and lines of maintenance treatment $(p>0.05)$ (Table 4).

The impact of TNFAIP3 ( $r 55029939$ C>G) SNP on the laboratory response to treatment in chronic PIT patients As regards the laboratory response to treatment, comparison between chronic PIT patients carrying the mutant heterozygous genotype (CG) achieving complete response and those with no response revealed nonstatistically significant difference between both groups 


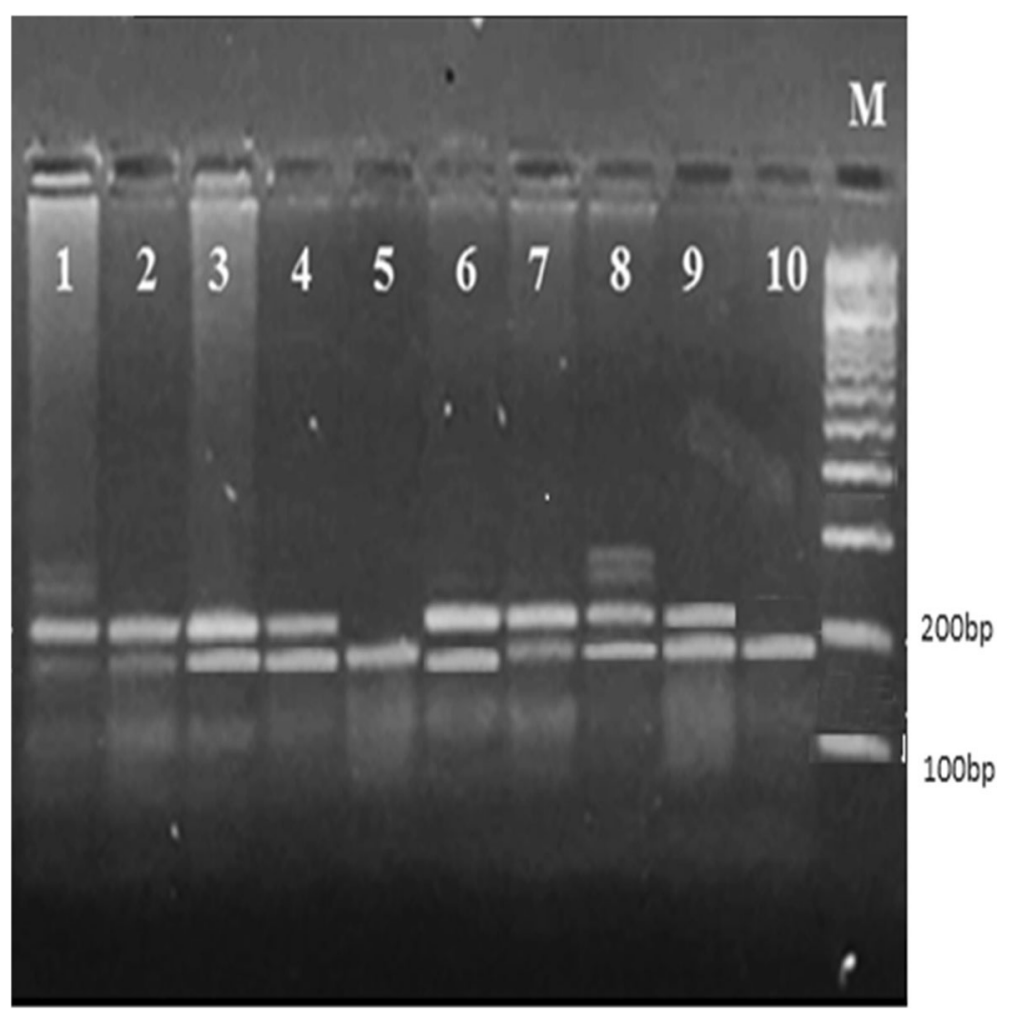

Fig. 1 Agarose gel electrophoresis of TNFAIP3 (rs5029939 C>G) SNP PCR products. Enzyme digestion products of TNFAIP3 rs5029939 (C>G) SNP using AFLII restriction enzyme. Lanes 1, 2, 3, 4, 6, 7, 8, and 9: mutant heterozygous genotype (CG); lanes 5 and 10: wild homozygous genotype (CC). M, DNA marker Ladder

[OR (95\% CI), 1.667 (0.165-16.810); $p>0.05]$. Similarly, the MAF of $r s 5029939-G$ was comparable between both groups [OR (95\% CI), 1.571 (0.175-14.111); $p>0.05$ ] with no liability of patients carrying TNFAIP3 (rs5029939 $C>G$ ) polymorphism to achieve complete response to treatment (Table 5).

\section{Discussion}

TNFAIP3 gene has been recognized as a major susceptibility gene for multiple auto-immune diseases [15]. Recently, GWAS revealed that there is a strong association of multiple SNPs in the TNFAIP3 gene, located on human chromosome 6p23, and psoriasis [20]. Subsequent studies confirmed its implication in other immune-mediated disorders, such as rheumatoid arthritis (RA), juvenile idiopathic arthritis, SLE [14], inflammatory bowel disease (IBD) [22], and ITP. The list of common variants in TNFAIP3 gene keeps expanding, with reported associations with several auto-immune diseases including ITP; however, little is known about the role of TNFAIP3 in the pathogenesis of ITP [15]. The current case-control study aimed to study the distribution of TNFAIP3 (rs5029939: $C>G$ ) polymorphism and the possible association of the studied

Table 2 Comparison between chronic PIT patients and healthy controls as regard demographic, clinical, and laboratory data

\begin{tabular}{|c|c|c|c|c|}
\hline \multicolumn{2}{|l|}{ Variables } & \multirow{2}{*}{$\begin{array}{l}\text { Chronic ITP }[\boldsymbol{n}=\mathbf{4 0}] \\
17(42.5)\end{array}$} & \multirow{2}{*}{$\begin{array}{l}\text { Controls }[\boldsymbol{n}=\mathbf{5 0 ]} \\
22(44 \%)\end{array}$} & \multirow{2}{*}{$\begin{array}{l}\boldsymbol{p} \text { value } \\
0.887\end{array}$} \\
\hline$\overline{\operatorname{Sex}[N(\%)]}$ & Male & & & \\
\hline & Female & $23(57.5)$ & $28(56 \%)$ & \\
\hline \multicolumn{2}{|c|}{ Age (mean $\pm \mathrm{SD})$} & $8.14 \pm 3.96$ & $7.93 \pm 3.82$ & 0.835 \\
\hline \multicolumn{2}{|c|}{ Platelets at the time of sampling $\left[\times 10^{9} / /(\right.$ mean $\left.\pm S D)\right]$} & $124 \pm 72.86$ & $286.36 \pm 80.9$ & $<0.001^{* *}$ \\
\hline \multicolumn{2}{|c|}{ Hemoglobin at the time of sampling $[\mathrm{g} / \mathrm{dl}($ mean $\pm \mathrm{SD})]$} & $10.98 \pm 1.45$ & $13.0 \pm 1.02$ & $<0.001^{* *}$ \\
\hline \multicolumn{2}{|c|}{ TLC at the time of sampling $\left[\times 10^{9} /(\right.$ mean $\left.\pm S D)\right]$} & $10 \pm 4.32$ & $8.03 \pm 1.84$ & $0.036^{*}$ \\
\hline
\end{tabular}

$T L C$ total leucocytic count

* Statistically significant

** highly statistically significant 
Table 3 Comparison of TNFAIP3 (rs5029939 C> G) genotype distribution and allele frequency between chronic PIT patients and controls

\begin{tabular}{lllll}
\hline TNFAIP3 $(\boldsymbol{r s 5 0 2 9 9 3 9 ~ C > G ) ~ S N P ~}$ & Chronic PIT patients $[\boldsymbol{n}=\mathbf{4 0}]$ & Control $[\boldsymbol{n = 5 0 ]}$ & $\boldsymbol{p}$ value & OR $(\mathbf{9 5} \%$ CI) \\
\hline CC genotype & $31(77.5 \%)$ & $41(82 \%)$ & Reference \\
CG genotype & $9(22.5 \%)$ & $9(18 \%)$ & 0.596 & $1.323(0.470-0.723)$ \\
Alleles & & & \\
C allele & $71(88.8 \%)$ & $91(91 \%)$ & Reference \\
G allele & $9(11.2 \%)$ & $9(9 \%)$ & 0.617 & $1.282(0.484-3.397)$ \\
\hline
\end{tabular}

polymorphism with the susceptibility to chronic PIT and the response to treatment in a sample of Egyptian pediatric chronic PIT patients. TNFAIP3 genotyping was tested by PCR-RFLP technique in 40 pediatric chronic PIT patients. Fifty age- and gender-matched healthy controls were subjected to the same analysis.

TNFAIP3 ( $r 55029939$ C >G) genotyping revealed a statistically non-significant different distribution among chronic PIT cases and controls [CC, $77.5 \%$ vs. $82.5 \%$, and CG, $22 \%$ vs. $18 \%$, respectively; OR ( $95 \% \mathrm{CI}), 1.323$ (0.470-0.723); $p$, 0.596]. The MAF of rs5029939-G was comparable between the 2 groups (0.11 vs. 0.09) [OR (95\% CI), 1.282 (0.4843.397); $p, 0.617$ ] (Table 3). Thus, this study demonstrated no statistically significant different TNFAIP3 (rs5029939 $C>G$ ) genotype distribution or allele frequency between chronic PIT patients and controls with no liability of patients carrying TNFAIP3 ( $r 5029939$ C>G) polymorphism to develop chronic course of the disease. Comparison between chronic PIT patients carrying the mutant heterozygous genotype (CG) achieving complete response and those with no response revealed non-statistically significant difference between both groups [OR (95\% CI), 1.667 (0.165$16.810) ; p>0.05]$. Similarly, the MAF of $r s 5029939-G$ was comparable between both groups [OR (95\% CI), 1.571 (0.175-14.111); $p>0.05$ ] (Table 5). Thus, this study showed no liability of patients carrying TNFAIP3 (rs5029939 C>G) polymorphism to achieve complete response to treatment. So we concluded that the variant genotype (CG) and the minor allele (rs5029939-G) are not risk factors for the susceptibility to chronic PIT and are not associated with response to treatment in the studied sample of Egyptian pediatric patients with chronic PIT.

Our results agreed with those of $\mathrm{Li}$ et al. [6] who investigated the frequency of four TNFAIP3 SNPs (rs5029939, rs2230926, rs6920220, and rs10499194) in the Chinese population. Compared to controls, only (rs10499194) SNP expression was significantly higher in ITP patients, while there was no statistically significant difference in genotype and allele frequencies regarding other SNPs including (rs5029939) between ITP subjects and controls. Moreover, no significant association of the studied SNPs with the severity or refractoriness of ITP was observed.
However, our results were discordant with those reported by Zhou et al. [15] who investigated TNFAIP3 ( $r s 2230926 T>G)$ and ( $r 55029939$ C>G) SNPs in the Chinese patients. They demonstrated that both (rs2230926 $T>G$ ) and (rs5029939 $C>G$ ) variants showed a statistically significant different genotype distribution between Chinese chronic PIT patients and controls [(TG, 23.3\% vs. 9.8\%) OR (95\% CI), 2.79 (1.51-5.18)], $p<$ 0.05 , and $[(\mathrm{CG}, 30.1 \%$ vs. $7.2 \%)$ OR (95\% CI), 5.57 (2.83-10.97)], $p<0.05$. Similarly, the minor alleles (rs2230926)-G and (rs5029939)-G showed a statistically significantly higher frequency in chronic PIT patients compared to controls $(11.6 \%$ vs. $4.9 \%)$ [OR (95\% CI), $2.56(1.41-4.64)], p<0.05$, and $(15.1 \%$ vs.3.6\%) [OR (95\% CI), 4.76 (2.47-9.17)], $p<0.05$, respectively. So they concluded that there is a statistically significant difference in TNFAIP3 (rs5029939 $C>G$ ) genotype distribution and allele frequency between both groups and that the variant genotypes of rs2230926 (TG) and rs5029939 (CG) and the mutant alleles (rs2230926)- $G$ and (rs5029939)-G are risk factors associated with the susceptibility to chronic PIT in Chinese children. The difference between their results and ours might be explained by the fact that the TNFAIP3 (rs5029939 C>G) variant genotype (CG) are variably expressed among different ethnic populations being more expressed in Chinese than Egyptian population, also environmental variation and epigenetic factors are kept in consideration. Besides, the potential for ancestry differences and admixture to affect the results of their genetic analyses

Zhou et al. [15] had concluded that TNFAIP3 ( $r s 2230926 T>G$ ) and ( $r 55029939$ C>G) SNPs might be associated with the susceptibility of chronic PIT in Chinese population, suggesting that TNFAIP3 gene might be added to the list of genes associated with chronic PIT. However, by this time, no previous researches were conducted to explore the effect of ( $r$ 5029939) variant located in Intron 2 on TNFAIP3 function in ITP patients, so they recommended further studies to explore the mechanisms how these two variants modulated the susceptibility of the disease. Moreover, Dieudé et al. [18] showed that (rs5029939) was in strong LD with (rs2230926) in 
Table 4 Comparison of wild (CC) and heterozygous mutant (CG) genotypes of TNFAIP3 (rs5029939 C>G) SNP in chronic PIT patients as regards platelet counts and treatment response

\begin{tabular}{|c|c|c|c|c|}
\hline \multirow[t]{2}{*}{ Chronic PIT patients } & & \multicolumn{3}{|l|}{ TNFAIP3 (rs5029939 C>G) SNP } \\
\hline & & Wild genotype (CC) [n= 31] & $\begin{array}{l}\text { Mutant heterozygous } \\
\text { genotype (CG) }[n=9]\end{array}$ & $p$ value \\
\hline \multirow[t]{2}{*}{ Sex $[N(\%)]$} & Males & $15(48.4)$ & $2(22.5)$ & 0.256 \\
\hline & Females & $16(51.6)$ & $7(77.8)$ & \\
\hline \multicolumn{2}{|l|}{ Age $($ mean $\pm S D)$} & $7.77 \pm 3.7$ & $9.4 \pm 4.74$ & 0.235 \\
\hline \multicolumn{2}{|c|}{ Age at initial presentation (mean $\pm S D$ ) } & $4.1 \pm 2.63$ & $5.91 \pm 3.59$ & 0.157 \\
\hline \multicolumn{2}{|l|}{ Duration of illness (mean $\pm \mathrm{SD}$ ) } & $3.7 \pm 2.53$ & $3.53 \pm 2.61$ & 0.702 \\
\hline \multirow[t]{3}{*}{ Type of bleeding $[N(\%)]$} & Cutaneous & $17(54.8)$ & $4(44.4)$ & 0.552 \\
\hline & Mucous & $1(3.2)$ & $1(11.1)$ & \\
\hline & Both & $13(41.9)$ & $4(44.4)$ & \\
\hline \multicolumn{5}{|l|}{ Severity of bleeding } \\
\hline \multirow[t]{5}{*}{ (IWG bleeding score) $[N(\%)]$} & Severe life threatening (4b) & $1(3.2)$ & $1(11.1)$ & 0.850 \\
\hline & Severe non-life threatening(4a) & $4(12.9)$ & $1(11.1)$ & \\
\hline & Moderate (3) & $12(38.7)$ & $4(44.4)$ & \\
\hline & Mild (2) & $13(41.9)$ & $3(33.3)$ & \\
\hline & Minor (1) & $1(3.2)$ & $0(0)$ & \\
\hline \multicolumn{2}{|l|}{ Splenectomy $[N(\%)]$} & $1(3.2)$ & $1(11.1)$ & 0.404 \\
\hline \multicolumn{2}{|l|}{ HTN $[N(\%)]$} & $9(29)$ & $4(44.4)$ & 0.437 \\
\hline \multicolumn{2}{|c|}{ Initial platelet count $\left[\times 10^{9} / \mathrm{L}(\right.$ mean $\left.\pm \mathrm{SD})\right]$} & $29.42 \pm 19$ & $43.89 \pm 20.36$ & 0.064 \\
\hline \multicolumn{2}{|c|}{ Platelets at the time of sampling $\left[\times 10^{9} /(\right.$ mean \pm SD) $]$} & $111.7 \pm 60.59$ & $166.11 \pm 97.66$ & 0.177 \\
\hline \multicolumn{2}{|c|}{ Hemoglobin at the time of sampling $[\mathrm{g} / \mathrm{dl}($ mean $\pm \mathrm{SD})]$} & $10.96 \pm 1.42$ & $11.07 \pm 1.65$ & 0.824 \\
\hline \multicolumn{2}{|c|}{ TLC at the time of sampling $\left[\times 10^{9} / /(\right.$ mean \pm SD) $]$} & $10.2 \pm 4.42$ & $9.33 \pm 4.14$ & 0.849 \\
\hline \multirow[t]{3}{*}{ Laboratory response $[N(\%)]$} & Complete response & $21(67.74)$ & $7(77.7)$ & 1 \\
\hline & Response & $5(16.12)$ & $1(11.1)$ & 0.697 \\
\hline & No response & $5(16.12)$ & $1(11.1)$ & 0.697 \\
\hline \multicolumn{5}{|l|}{ Treatment received } \\
\hline \multirow[t]{4}{*}{ Initial treatment $[N(\%)]$} & Watchful waiting & $5(16.1)$ & $6(66.7)$ & $0.007^{*}$ \\
\hline & Corticosteroids & $31(100)$ & $9(100)$ & - \\
\hline & IVlg & $4(12.9)$ & $0(0)$ & --- \\
\hline & Platelet transfusion & $1(3.2)$ & $1(11.1)$ & 0.404 \\
\hline \multirow[t]{6}{*}{ Maintenance treatment $[N(\%)]$} & Oral corticosteroids & $26(83.9)$ & $9(100)$ & 0.570 \\
\hline & Azathioprine (Imuran) & $19(61.3)$ & $5(55.6)$ & 1 \\
\hline & Cyclosporine (Sand immune) & $5(16.1)$ & $3(33.3)$ & 0.348 \\
\hline & Mycophenolate Mofetil (Cellcept) & $0(0)$ & $1(11.1)$ & --- \\
\hline & Eltrombopag (Revolade) & $2(6.5)$ & $0(0)$ & --- \\
\hline & Oral corticosteroids & $26(83.9)$ & $9(100)$ & 0.570 \\
\hline
\end{tabular}

HTN hypertension, $I V I g$ intravenous immunoglobulin

* Statistically significant

European Caucasian population. However, unlike the European Caucasian population, Zhou et al. [15] did not find a tight LD between both variants in Chinese population. So further studies to explore the role of (rs5029939) variant in the pathogenesis of PIT as well as the LD between (rs5029939) and (rs2230926) were recommended.
As regards studying TNFAIP3 (rs5029939 C>G) variant in other auto-immune diseases, our results agreed with those of Yang et al. [23] who investigated the frequency of TNFAIP3 ( $r 55029939$ C>G) SNP in the Chinese population with myasthenia gravis (MG). Compared to controls, TNFAIP3 (rs5029939 C>G) SNP expression 
Table 5 The impact of TNFAIP3 (r55029939 C> G) SNP on the laboratory response to treatment in chronic PIT patients

\begin{tabular}{lllll}
\hline TNFAIP3 $(r$ 5029939 C>G) SNP & Complete response & No response & $p$ value & OR (95\% CI) \\
\hline CC genotype & $21(67.7 \%)$ & $5(16.1 \%)$ & Reference & $1.997(0.165-16.810)$ \\
CG genotype & $7(77.7 \%)$ & $1(16.6 \%)$ & & \\
Alleles & & & & \\
$\quad$ C allele & $49(0.79)$ & $11(0.18)$ & Reference & $1.571(0.175-14.111)$ \\
G allele & $7(0.39)$ & $1(0.05)$ & 1 & \\
\hline
\end{tabular}

was not significantly higher in patients' group. The distribution of the variant genotypes in the MG subjects and controls [CG, $8 \%$ vs. 8.1 , and GG, $0.5 \%$ vs. $0 \%$, respectively, $p$ 0.880]. The minor allele ( $r s 5029939-G)$ was comparable between MG patients and controls $(4.5 \%$ vs. $4 \%), p$ 0.750. So it was concluded that the variant genotypes (CG/GG) and the minor allele (rs5029939-G) were not risk factors for the susceptibility to MG disease. A meta-analysis was done by Lee and Song [24] who considered 8 studies of ethnically different groups (4 Asian [16, 22, 25, 26], 3 European [18, 27, 28], and one African American [29]), to investigate whether the TNFAIP3 polymorphisms including (rs5029939 $C>G$ ) SNP contribute to SLE susceptibility in different populations. They found out that the allelic frequencies of genes often differ considerably in different ethnic groups, and thus ethnically specific association studies are required to determine genetic associations in different populations. They confirmed the association of TNFAIP3 ( $r s 5029939$ C $>G$ ) SNP with SLE in Europeans and Asians. These findings suggest that the role of TNFAIP3 polymorphism in immune-mediated diseases is controversial and might be organ-specific.

\section{Conclusion}

To the best of our knowledge, this is the first study to analyze the distribution of TNFAIP3 ( $r 55029939 C>G$ ) SNP in the Egyptian children with chronic PIT and to investigate the possible role of the studied polymorphism in the pathogenesis and the response to treatment in PIT. It showed no liability of patients carrying TNFAIP3 (rs5029939 C>G) polymorphism to develop chronic course of the disease or to achieve complete response to treatment. So it was concluded that TNFAIP3 (rs5029939 $C<G$ ) polymorphism plays no role in either susceptibility to chronic PIT in the studied sample of Egyptian pediatric population or their response to treatment.

\section{Recommendations}

These results must be verified by further studies enrolling a larger cohort of patients to gain greater insight into the potential role of the TNFAIP3 (rs5029939 $C>G$ ) gene polymorphism in the pathogenesis and treatment response of PIT. Further studies are also recommended to detect other polymorphisms in TNFAIP3 gene such as (rs2230926) and (rs10499194) in the Egyptian children to investigate the specific ethnic makeup of our patients. Additional studies on PIT patients of adult age group or different ethnic populations are needed to better understand the role of the studied polymorphism in the pathogenesis of PIT and hence facilitate the discovery of new therapeutic strategies.

\section{Abbreviations}

CARD8: Caspase recruitment domain 8; CR: Complete response;

DCs: Dendritic cells; DUB activity: De-ubiquitinating activity; FCRL3: FC Receptor Like 3; GWAS: Genome-wide association studies; IBD: Inflammatory bowel disease; IL-1A: Interleukin-1A; IL-2: Interleukin-2; IL-6: Interleukin-6; IL10: Interleukin-10; IL-17F: Interleukin-17F; INF-Y: Interferon-gamma; IRF5: Interferon Regulatory Factor 5; ITGAM: Integrin Subunit Alpha M; ITP: Immune thrombocytopenic purpura; IWG: International working group; LD: Linkage disequilibrium; MAF: Minor allele frequency; MG: Myasthenia gravis; MSCs: Mesenchymal stem cells; NF-KB: Nuclear factor KB; NLRP3: NLR family pyrin domain containing 3; NR: No response; OUT: Ovarian tumor domain; PCR-RFLP: Polymerase chain reaction-restriction fragment length polymorphism; PIT: Primary immune thrombocytopenia; PTPN22: Protein tyrosine phosphatase, non-receptor type 22; R: Response; RA: Rheumatoid arthritis; SH2B3: The SH2B adaptor protein 3; SLE: Systemic lupus erythematosus; SNP: Single-nucleotide polymorphism; STAT4: Signal transducer and activator of transcription 4; TGF- $\beta 1$ : Transforming growth factor Beta-1; TNF: Tumor Necrotic Factor; TNF-a: Tumor Necrosis Factor alpha; TNFAIP3: Tumor Necrosis Factor Associated Induced Protein-3; TNF$\beta$ : Tumor Necrosis Factor Beta; TRAF1: Tumor necrosis factor receptor (TNFR) associated factor $1 ; \mathrm{ZnF}$ domain: Zinc finger domain

\section{Acknowledgements}

Not applicable

\section{Authors' contributions}

Dr. 'MA': designing the study and work supervision; Dr. 'DM': supervision, validation, and final approval of the version to be submitted for publication; Dr. 'SB': analysis and interpretation of data; Dr. 'BM': data collection and analysis; and Dr. 'MY': writing the manuscript. We affirm that the submission represents original work that has not been published previously and is not currently being considered or submitted to another journal until a decision has been made. Also, we confirm that the manuscript has been read and approved by all the authors and each author believes that the manuscript represents honest work and be able to verify the validity of the reported results. There is no published work that concerns the same patients included in the current study. This work received no specific grant from any funding source. The authors have no conflict of interest to declare.

\section{Funding}

Not applicable

\section{Availability of data and materials}

Not applicable

\section{Ethics approval and consent to participate}

The study protocol was approved by the Council of Pediatrics Department, Faculty of Medicine, Cairo University, held on May 2016. Ethical committee approval reference number is $1-210414$. 
An informed written consent was obtained from all subjects' legal guardians in accordance with the Declaration of Helsinki and the hospital-based ethics committee as well.

\section{Consent for publication}

Not applicable

\section{Competing interests}

The authors have no conflicts of interest to declare.

\section{Author details}

'Pediatric Department, Kasr Al-Ainy School of Medicine, Cairo University, Kasr Al-Ainy St., Cairo 11562, Egypt. ${ }^{2}$ Clinical and Chemical Pathology Department, Kasr Al-Ainy School of Medicine, Cairo University, Kasr Al-Ainy St., Cairo 11562, Egypt.

Received: 3 October 2020 Accepted: 29 December 2020

Published online: 08 February 2021

\section{References}

1. Raj AB (2017) Immune thrombocytopenia: pathogenesis and treatment approaches. J Hematol Transfus 5:1056-1065

2. Rodeghiero F, Stasi R, Gernsheimer T (2009) Standardization of terminology, definitions and outcome criteria in immune thrombocytopenic purpura of adults and children: report from an international working group. Blood 113: 2386-2393

3. Stasi R (2011) Pathophysiology and therapeutic options in primary immune thrombocytopenia. Blood Transfus 9:262-273

4. Godeau B (2014) Immune thrombocytopenic purpura: major progress in knowledge of the pathophysiology and the therapeutic strategy, but still a lot of issues. Presse Med 43:47-48

5. Cines DB, McMillan R (2007) Pathogenesis of chronic immune thrombocytopenic purpura. Curr Opin Hematol 14(5):511-514

6. Li J, Ma S, Shao L, Ma C, Gao C, Zhang X et al (2017) Inflammation-related gene polymorphisms associated with primary immune thrombocytopenia. Front Immunol 8:744

7. Huang J, Yang Y, Liang Z, Kang M, Kuang Y, Li F (2015) Association between the CD24 Ala57Val polymorphism and risk for multiple sclerosis and systemic lupus erythematosus: a meta-analysis. Sci Rep 5:9557

8. Vereecke L, Beyaert R, van Loo G (2011) Genetic relationships between A20/ TNFAIP3, chronic inflammation, and autoimmune disease. Biochem Soc Trans 39:1086-1091

9. Coornaert B, Carpentier I, Beyaert R (2009) A20: central gatekeeper in inflammation and immunity. J Biol Chem 284:8217-8221

10. Wertz IE, O'Rourke KM, Zhou H, Eby M, Aravind L, Seshagiri S et al (2004) De-ubiquitination and ubiquitin ligase domains of A20 downregulate NFkappaB signalling. Nature 430(7000):694-699

11. Kool M, van Loo G, Waelput W, De Prijck S, Muskens F, Sze M et al (2011) The ubiquitin-editing protein A20 prevents dendritic cell activation, recognition of apoptotic cells, and systemic autoimmunity. Immunity 35(1): $82-96$

12. Lee EG, Boone DL, Chai S, Libby SL, Chien M, Lodolce JP et al (2000) Failure to regulate TNF-induced NF-kappaB and cell death responses in A20deficient mice. Science 289(5488):2350-2235

13. Hammer GE, Turer EE, Taylor KE, Fang CJ, Advincula R, Oshima S et al (2011) Expression of A20 by dendritic cells preserves immune homeostasis and prevents colitis and spondyloarthritis. Nat Immunol 12(12):1184-1193

14. Kim SK, Choe JY, Bae J, Chae SC, Park DJ, Kwak SG et al (2014) TNFAIP3 gene polymorphisms associated with differential susceptibility to rheumatoid arthritis and systemic lupus erythematosus in the Korean population. Rheumatology (Oxford) 53:1009-1013

15. Zhou H, Yang J, Liu L, Zhang D, Zhou K, Li H et al (2015) The polymorphisms of tumor necrosis factor-induced protein 3 gene may contribute to the susceptibility of chronic primary immune thrombocytopenia in Chinese population. Platelets 27:26-31

16. He Y, Xu LL, Feng FE, Wang QM, Zhu XL, Wang CC et al (2018) Mesenchymal stem cell deficiency influences megakaryocytopoiesis through the TNFAIP 3/NF-kB/SMAD pathway in patients with immune thrombocytopenia. Brit J Hematol 180:395-411
17. Musone SL, Taylor KE, Lu T,, Nititham J, Ferreira RC, Ortmann W et al (2008) Multiple polymorphisms in the TNFAIP3 region are independently associated with systemic lupus erythematosus. Nat Genet 40(9):1062-1064

18. Dieudé P, Guedj M, Wipff J, Ruiz B, Riemekasten G, Matucci-Cerinic M et al (2010) Association of the TNFAIP3 rs5029939 variant with systemic sclerosis in the European Caucasian population. Ann Rheum Dis 69(11):1958-1964

19. Lodolce JP, Kolodziej LE, Rhee L, Kariuki SN, Franek BS, McGreal NM (2010) African-derived genetic polymorphisms in TNFAIP3 mediate risk for autoimmunity. J Immunol 184:7001-7009

20. Tejasvi T, Stuart PE, Chandran V, Voorhees JJ, Gladman DD, Rahman P et al (2012) TNFAIP3 gene polymorphisms are associated with response to TNF blockade in psoriasis. J Invest Dermatol 132:593-600

21. Das T, Chen Z, Hendriks RW, Kool M (2018) A 20/tumor necrosis factor ainduced protein 3 in immune cells controls development of autoinflammation and autoimmunity: lessons from mouse models. Front Immunol 9:104

22. Bank S, Andersen PS, Burisch J, Pedersen N, Roug S, Galsgaard J et al (2014) Associations between functional polymorphisms in the NF-KB signaling pathway and response to anti-TNF treatment in Danish patients with inflammatory bowel disease. Pharmacogenomics J 14:526-534

23. Yang HW, Xie $Y$, Zhao $Y$, Sun L, Zhu X, Wang $S$ et al. TNFAIP3 gene rs7749323 polymorphism is associated with late onset myasthenia gravis. Medicine (Baltimore). 2017;96(20):e6798

24. Lee YH, Song GG (2012) Associations between TNFAIP3 gene polymorphisms and systemic lupus erythematosus: a meta-analysis. Genet Test Mol Biomarkers 16:1105-1110

25. Kawasaki A, Ito I, Ito S, Hayashi T, Goto D, Matsumoto I, et al. Association of TNFAIP3 polymorphism with susceptibility to systemic lupus erythematosus in a Japanese population. J Biomed Biotechnol. 2010;2010:207578.

26. Shimane K, Kochi Y, Horita T, Ikari K, Amano H, Hirakata M (2010) The association of a nonsynonymous single-nucleotide polymorphism in TNFA IP3 with SLE and RA in the Japanese population. Arthritis Rheum 62:574579

27. Cai LQ, Wang ZX, Lu WS, Han JW, Sun LD, Du WH et al (2010) A singlenucleotide polymorphism of the TNFAIP3 gene is associated with systemic lupus erythematosus in Chinese Han population. Mol Biol Rep 37:389-394

28. Graham RR, Cotsapas C, Davies L, Hackett R, Lessard CJ, Leon JM (2008) Genetic variants near TNFAIP3 on 6q23 are associated with SLE. Nat Genet 40:1059-1061

29. Bates JS, Leassard CJ, Leon JM, Nguyen T, Battiest LJ, Rodgers J (2009) Metaanalysis and imputation identifies a $109 \mathrm{~kb}$ risk haplotype spanning TNFAIP3 associated with lupus nephritis and hematologic manifestations. Genes Immun 10:470-477

\section{Publisher's Note}

Springer Nature remains neutral with regard to jurisdictional claims in published maps and institutional affiliations.

\section{Submit your manuscript to a SpringerOpen ${ }^{\bullet}$ journal and benefit from:}

- Convenient online submission

- Rigorous peer review

- Open access: articles freely available online

- High visibility within the field

- Retaining the copyright to your article

Submit your next manuscript at $>$ springeropen.com 